\title{
Inclusão de alunos autistas como percursos da redução dos danos causados pelo desprezo social: uma revisão bibliográfica
}

\author{
Inclusion of autistic students as ways to reduce the damage caused by social contempt: a \\ bibliographic review
}

\begin{abstract}
Inclusión de estudiantes autistas como formas de reducir el daño causado por el desprecio social: una revisión bibliográfica
\end{abstract}

\begin{abstract}
Edmar Reis Thiengo ${ }^{1 *}$, Aleziani Scherrer Santos ${ }^{1}$, Edilcia das Neves Sant'Ana Sedano Neves ${ }^{1}$, Juliana Pereira Costalonga ${ }^{1}$, Leonardo dos Santos Cordeiro ${ }^{1}$, Vilma Alves Ramos Talyuli ${ }^{1}$, Francieli da Costa Pinto Costalonga ${ }^{1}$, Viviane Santiago de Jesus Leite ${ }^{1}$, Lyvian Teixeira Borges ${ }^{1}$, Jossieli Lucio Pereira de Freitas ${ }^{1}$.
\end{abstract}

\section{RESUMO}

Objetivo: Trata-se de estudo inclinado a analisar a literatura que trata da inclusão de alunos autistas como forma de reduzir os danos à sua saúde mental, causados pelo abandono e desprezo social. Revisão bibliográfica: Diante dos inúmeros problemas enfrentados na defesa da inclusão como forma de tratamento e de reduzir os impactos dos transtornos nas pessoas que os possuem, torna-se necessário analisar profundamente os efeitos do desprezo social aos alunos com autismo, como isso influência na sua vida escolar e quais políticas públicas ou novas ações do cotidiano estudantil podem ser adotados para reduzir danos à sua saúde mental. Tratar de inclusão social para os alunos com autismo, perpassa por uma série de conceitos e necessidades instrutivas, como evitar as abordagens demonstrando pena, incapacidade mental e qualquer tratamento que reduza a condição humana do aluno. Considerações finais: Este estudo está debruçado em pesquisas teóricas publicadas que abordam temas iguais ou parecidos, e se inspira na forte proposta de inclusão dos inúmeros programas sociais já existentes ou propostos, almejando promover a saúde mental do aluno autista.

Palavras-chave: Saúde mental, Saúde, Inclusão.

\begin{abstract}
Objective: This is a study inclined to analyze the literature that deals with the inclusion of the autistic student as a way to reduce the damage to their mental health, caused by abandonment and social contempt. Bibliographic review: In view of the numerous problems faced in the defense of inclusion as a form of treatment and to reduce the impacts of disorders on its patients, it is necessary to deeply analyze the effects of social contempt on students with autism, how this influences their lives what public policies or new actions of the student's daily life can be adopted to reduce damage to their mental health. Dealing with social inclusion for the student with autism, goes through a series of concepts and instructional needs, such as avoiding approaches demonstrating pity, mental disability and any treatment that reduces the student's human condition. Final considerations: This study focuses on published theoretical research that addresses the same or similar themes, and is inspired by the strong proposal to include the countless existing or proposed social programs, aiming to promote the mental health of the autistic student.
\end{abstract}

Key words: Mental health, Health, Inclusion.

${ }^{1}$ Faculdade Vale do Cricaré (FVC), São Mateus - ES. *E-mail: thiengo.thiengo@gmail.com

SUBMETIDO EM: $8 / 2020$

ACEITO EM: 9/2020

PUBLICADO EM: 2/2021 


\section{RESUMEN}

Objetivo: Este es un estudio inclinado a analizar la literatura que trata sobre la inclusión del estudiante autista como una forma de reducir el daño a su salud mental, causado por el abandono y el desprecio social. Revisión bibliográfica: En vista de los numerosos problemas enfrentados en la defensa de la inclusión como forma de tratamiento y para reducir los impactos de los trastornos en sus pacientes, es necesario analizar profundamente los efectos del desprecio social en los estudiantes con autismo, cómo esto influye en sus vidas qué políticas públicas o nuevas acciones de la vida diaria del estudiante pueden adoptarse para reducir el daño a su salud mental. Al tratar la inclusión social del alumno con autismo, se pasan por una serie de conceptos y necesidades de instrucción, como evitar enfoques que demuestren pena, discapacidad mental y cualquier tratamiento que reduzca la condición humana del alumno. Consideraciones finales: Este estudio se centra en la investigación teórica publicada que aborda los mismos temas o temas similares, y se inspira en la fuerte propuesta de incluir los innumerables programas sociales existentes o propuestos, con el objetivo de promover la salud mental del estudiante autista.

Palabras clave: Salud mental, Salud, Inclusión.

\section{INTRODUÇÃO}

Para Silva M e Mulick JA (2009), o autismo faz parte de um grupo de distúrbios do desenvolvimento neurológico chamado Transtornos Globais do Desenvolvimento (TGDs), Transtornos Invasivos do Desenvolvimento (TID) ou Transtornos do Espectro do Autista (TEA). Esse grupo de doenças compartilha os principais sintomas de comprometimento em três áreas específicas do desenvolvimento, a saber: déficits nas habilidades sociais, déficits nas habilidades de comunicação (verbal e não verbal) e comportamentos restritos, repetitivos e estereotipados, interesses e/ou atividades. Além do autismo, a antes chamada síndrome de Asperger e hoje tratada como autismo brando, doenças de desintegração infantil (ou outras doenças de desintegração infantil), doença ou síndrome de Reiter e distúrbios globais do desenvolvimento não especificados (incluindo autismo atípico).

Desde os anos 90, de acordo com a Declaração de Jomtien (também conhecida como Declaração Universal de Educação para Todos) e a Convenção sobre os Direitos da Criança (1989) e a Declaração de Salamanca, foi estabelecido que todos (crianças, jovens e adultos) deve receber as oportunidades educacionais que atendem às suas necessidades de aprendizado. Portanto, devido à necessidade de prestar atenção especial às pessoas com deficiência, devem ser tomadas medidas para garantir que as pessoas com deficiência tenham igual acesso à educação, que é parte integrante do sistema educacional (CABRAL CS e MARIN AH, 2017).

No século passado, as pessoas se interessaram pela questão da interação social e refletiram sobre sua importância para o comportamento humano. Entre 1830 e 1930, já era possível encontrar uma variedade de produtos, que pressupunham que as relações sociais interpessoais eram um dos principais determinantes da natureza humana e exigiam pesquisa científica. Mesmo assim, destacou-se a importância da experiência social com os pares. Na época, as ideias geradas durante esse período eram mais especulativas, porque ainda não havia sido estabelecida uma base empírica consistente e ainda não tinha estabelecida uma abordagem sistemática para a coleta de dados nesse campo. Foi depois da década de 1930 que métodos e técnicas de observação em grupo foram desenvolvidos, especialmente instrumentos sociais de medição (CAMARGO SPH e BOSA CA, 2009).

Em outras palavras, a prática de excluir as pessoas que foram ignoradas pelo governo e pela sociedade é visível na história. A partir do século XVIII, esse período foi caracterizado pelo movimento de exclusão, e as pessoas com deficiência estavam excluídas da vida social por não terem direitos. A sociedade não os aceitou, então eles precisavam morar com prisioneiros imitando os, naquele período, chamados de louco, que ficavam isolados em internações em tempo integral. Mais tarde, aproximando-se do século XIX, foi realizada uma campanha de isolamento parcial para pessoas com deficiência, que, de acordo com seu potencial e 
habilidades, eram destinadas a entrar em instituições específicas (APAE e outras instituições similares) para tratamento, educação e treinamento no trabalho (FINK IC, 2018).

No entanto, apesar das diretrizes, resoluções e parâmetros relacionados à inclusão de pessoas com deficiência, a prática ainda está longe de todas as propostas sobre a inclusão de pessoas com deficiência, e existem poucas medidas para promover treinamento e educação inclusiva para pessoas com deficiência. Nas salas de aula regulares em que esses alunos estão incluídos os professores também não receberam a graduação necessária para estudar estratégias e desenvolver práticas inclusivas. Em termos de inclusão, é necessário ir além da perspectiva das pessoas com deficiência e continuar discutindo a relação que a escola estabeleceu com "diferentes", como aceitá-la e como apresentá-la a outros alunos (GONÇALVES LP, et al., 2014).

Estudos realizados em vários países e até no Brasil afirmaram a importância de educar crianças de 0 a 6 anos. Essa importância não se reflete apenas no processo educacional subsequente, mas também no treinamento de indivíduos de uma perspectiva mais global. Nos últimos dez anos, a divulgação desses resultados promoveu o desenvolvimento, pelo governo, de planos para a educação infantil em nossa sociedade, e com isso, foi elaborado o novo Plano Nacional de Educação (PNE, 2014).

A ideia de integração, que está em discussão desde o final da década de 60 , é responsável por mudar o paradigma da exclusão social. Inicialmente, essa abordagem tentou incluir pessoas com deficiência no sistema social geral de educação, trabalho, família e lazer; com base no "modelo médico da deficiência", foi necessário incluir as pessoas com deficiência com base nesse modelo de habilitação, reabilitação, educação, para que ele possa atender aos padrões reconhecidos no ambiente social (LEMOS ELMD, 2012).

Os objetivos dessa revisão são: expressar através da matéria já confeccionada as propostas de inclusão do aluno com espectro autista e abordar cientificamente como a exclusão e o isolamento desses alunos causa danos à saúde mental e não colabora de nenhuma maneira para seu tratamento. A ideia também é abordar as variadas formas de tratamentos que a sociedade utiliza com pessoas autistas a fim de instruir como que os tratamentos diferenciados agem como forma de exclusão e potencial causador de adoecimento desse público.

\section{REVISÃO BIBLIOGRÁFICA}

Desde 1994, o autismo é incluído na política educacional e a política nacional de educação especial e era classificado como um comportamento atípico. De acordo com a quarta edição do o Manual Diagnóstico e Estatístico de Transtornos Mentais (DSM IV-TR), na Política Nacional de Educação Especial na Perspectiva da Educação Inclusiva (PNEEPEI), o idioma oficial (Transtorno Global do Desenvolvimento) o termo comportamento atípico foi substituído. O DSM IV é organizado pela American Psychiatric Association (APA) e possui as seguintes categorias de autismo: síndrome de Rett, autismo infantil, síndrome de Asperger, doença de desintegração infantil e distúrbios globais do desenvolvimento (WUO AS, 2019).

A definição de autismo começou em 1943, quando Leo Kanner a descreveu pela primeira vez em um artigo intitulado: Distúrbios Autísticos do Contato Afetivo. Transtorno do espectro do autismo (TEA) afeta o processamento de informações no cérebro e causa sintomas, incluindo interação e comunicação social prejudicadas, interesse restrito e comportamentos repetitivos, geralmente detectados na primeira infância. $O$ TEA é definido pela interação entre vários genes e fatores ambientais. Estudos com gêmeos de um único ovo mostraram uma taxa de concordância incompleta, o que exacerba a contribuição de fatores ambientais para a etiologia do TEA. Pesquisas moleculares destacam que a epigenética do desenvolvimento cerebral pode ser uma causa potencial dessa doença (MAIA FA, et al., 2018).

Sabemos que hoje a educação integrada é objeto de pesquisa de muitos professores que buscam lançar um plano de desenvolvimento educacional, e os que já o fizeram contribuíram para fortalecer o processo de integração das escolas. No entanto, percebemos que o desafio está aumentando a cada ano, e não podemos deixar de refletir sobre esse tópico, principalmente porque recebemos estudantes em sala de aula todos os dias que precisam de uma compreensão mais detalhada do processo de aprendizagem. Alunos com variadas 
condições, deficiências físicas, visuais, intelectuais, alta habilidade/genialidade e distúrbios recentes do espectro do autismo (BENINI W e CASTANHA AP, 2016).

A inclusão ainda é uma nova realidade para os professores. A existência de alunos com necessidades educacionais especiais faz com que os educadores se sintam desamparados e frustrados e quando enfrentam as limitações dos alunos e suas próprias limitações, porque eles não podem fornecer atendimento personalizado a esses alunos. Para conseguir uma estratégia adequada, os professores devem sempre procurar e manter contato visual com os alunos com autismo, promover a comunicação, usar linguagem simples e clara para mediar jogos entre os alunos e usar recursos como computadores, músicas e livros para observar as crianças. Esses recursos são úteis para o aprendizado e despertam o interesse do aluno (BARBERINI KY, 2016).

Para Martins ADF e Monteiro MIB (2017), a teoria cognitiva pode ajudar a entender a função cognitiva e o comportamento desta doença, embora não exista uma teoria específica para provar ou explicar o autismo. Até a década de 1970, as mudanças cognitivas observadas nos casos de autismo não eram levadas em consideração porque enfatizavam os aspectos sociais e emocionais da doença.

Com novas diretrizes curriculares e legislação voltada à inclusão de pessoas com necessidades educacionais especiais, notamos que os alunos com autismo estão sendo incluídos nas escolas regulares. Até recentemente, essas crianças frequentavam apenas instituições especiais, não focadas na escola, mas no desenvolvimento de habilidades diárias e na eliminação de comportamentos considerados inadequados. Independentemente de os alunos com autismo frequentarem escolas regulares ou escolas especiais, é discutida a educação dessas crianças, que exige um melhor entendimento da relação entre alunos e colegas, equipes de ensino e outras instituições, pensando na possibilidade de ensinar esses alunos (MARTINS ADF e MONTEIRO MIB, 2017).

Torna-se de extrema importância tratar as questões relacionadas ao desprezo social e aos tratamentos diferenciados, que nada colaboram para a inserção do aluno com espectro autista na sociedade. $O$ aluno com espectro autista na maioria das vezes compreende o mundo ao seu redor, e não deixa de notar como o tratamento com ele é diferenciado, o que pode fazê-lo sentir-se excluído dos meios sociais. A demonstração de pena, adoção de uma superproteção e tratamento especial em todas as situações, induz os grupos que observam a fazer o mesmo, e a ideia é buscar meios de fazer a pessoa com espectro autista se sentir integrada, parte, membro da comunidade em que frequenta (NUNES DRP e SCHMIDT C, 2019).

\section{Propostas de inclusão do aluno com espectro autista}

No mundo ocidental, especialmente desde os anos 80 , a tolerância social tornou-se um lema para promover importantes movimentos sociais e ações políticas. Na Europa e nos Estados Unidos da América, desde a década de 1970, a integração social de pessoas com deficiência era um dos direitos sociais básicos expressos em importantes documentos legais e regulatórios. Gradualmente, as sociedades democráticas têm se espalhado, discutido e defendido a inclusão como o direito de todas as pessoas em relação a vários espaços sociais. A inclusão escolar é o tema de conferências internacionais, como a Conferência Mundial de Educação para Todos, realizada em Jomtien (Tailândia), em 1990, e a Conferência Mundial de Necessidades Educativas Especiais: Acesso e Qualidade, em 2000. Realizada em Salamanca, Espanha, em 1994, com a cooperação da Organização das Nações Unidas para a Educação, a Ciência e a Cultura (UNESCO) (MAZZOTTA MJS e D'ANTINO MEF, 2011).

Apesar do apoio fornecido pelas leis atuais do Brasil, ainda existem muitos pontos fracos na integração com a educação e dificuldades na implementação. Alguns estudos apontam que, entre outras, são necessárias mudanças na estrutura, recursos, ideologia e treinamento. A cada ano, o número de estudantes que recebem educação especial no sistema escolar formal está aumentando. No censo escolar do Instituto Nacional de Estudos e Pesquisas Educacionais Anísio Teixeira (INEP) de 2016, é possível verificar que 57,8\% das escolas no Brasil têm alunos que frequentam aulas regulares para grupos-alvo de educação especial, em comparação com $31 \%$ em 2008 . No entanto, ainda não há garantia de sua persistência na educação formal e da oportunidade de receber educação de qualidade (ADURENS FDL e VIEIRA CM, 2018). 
No Brasil, por diferentes razões, foram formuladas tardiamente medidas governamentais especificamente destinadas a acolher pacientes autistas. No início do século XXI, antes da publicação de políticas públicas sobre saúde mental de crianças e adolescentes, essa população só podia obter ajuda em instituições de caridade, por exemplo, Associação Pestalozzi e Associação dos Pais e Amigos dos Excepcionai (APAE) ou organizações não-governamentais (OLIVEIRA BDC, et al., 2017).

Ainda para Oliveira BDC, et al. (2017), o conflito posterior desta questão significa que a atual construção da política pública do Brasil sobre o autismo é marcada por dois grupos diferentes que se desenvolveram simultaneamente na história: por um lado, o maior grupo composto é parcialmente composto por grupos de profissionais das áreas psicossociais. Trabalhadores e gerentes da área de enfermagem, além de apoiantes da reforma psiquiátrica e membros de ações diretamente relacionadas à política pública de saúde mental do Sistema único de Saúde (SUS). A outra é a Associação de Pais e Familiares de Pacientes Autistas, que começaram a desenvolver suas próprias estratégias de assistência para os filhos na década de 1980 , marcada pela falta de recursos públicos para atender o cliente. A coexistência desses grupos e o paralelismo de suas propostas precisam ser determinados caso a caso, para que possam ajudar no debate sobre a atual disputa no caminho da política do autismo.

Em 2014, o Ministério da Saúde publicou um documento que estabeleceu diretrizes mais específicas para focar na reabilitação de pacientes com Transtorno de Espectro Autista. Ele contém informações sobre sinais de desenvolvimento do Autismo e problemas de comportamento, algumas ferramentas de triagem do autismo, avaliação e classificação diagnósticas e diretrizes de planejamento de tratamento. Em suma, da descoberta do risco ao diagnóstico e intervenção para reabilitação, o Ministério da Saúde fornece orientações sobre como a rede de atendimento deve acompanhar pacientes autistas (ARAUJO JAMR, et al., 2019).

Em 2015, o Ministério da Saúde publicou outro documento chamado linha direta de cuidados para pacientes com distúrbios do espectro do autismo e suas famílias, na Rede de Atenção Psicossocial do Sistema Único de Saúde, que fornece informações para gerentes e profissionais. As organizações de redes de enfermagem orientaram os métodos de tratamento especificamente para a reabilitação/habilitação de pacientes autistas do SUS, na intenção de posicionar a implementação de serviços de enfermagem para pessoas com transtorno do espectro autista (ARAUJO JAMR, et al., 2019).

A Lei no 13997 de 2020, criou a Carteira de Identificação da Pessoa com Transtorno do Espectro Autista (CIPTEA). O padrão é chamado Lei Romeo Mion, ele é filho do apresentador de TV Marcos Mion, que sofre de transtorno do espectro autista. As sanções foram emitidas em 9 de janeiro de 2019.0 texto alterou a Lei Berenice Piana de o 12.764 do ano de 2012, que estabeleceu uma política nacional para proteger os direitos das pessoas com distúrbios do espectro do autismo. De acordo com a nova lei, a CIPTEA deve garantir que a pessoa com autismo receba total atenção no que se refere a prestação de serviços rapidamente e tenha a garantia da participação e acesso a serviços públicos e privados, especialmente nos campos da saúde, educação e assistência social (BRASIL, 2019). A lei determina que:

"Art. $1^{\circ}$ Esta Lei, denominada "Lei Romeo Mion", altera a Lei no 12.764, de 27 de dezembro de 2012 (Lei Berenice Piana), e a Lei no 9.265, de 12 de fevereiro de 1996 (Lei da Gratuidade dos Atos de Cidadania), para criar a Carteira de Identificação da Pessoa com Transtorno do Espectro Autista (Ciptea), de expedição gratuita".

"Art. $3^{\circ}-A$. É criada a Carteira de Identificação da Pessoa com Transtorno do Espectro Autista (Ciptea), com vistas a garantir atenção integral, pronto atendimento e prioridade no atendimento e no acesso aos serviços públicos e privados, em especial nas áreas de saúde, educação e assistência social.§ $1^{\circ}$ A Ciptea será expedida pelos órgãos responsáveis pela execução da Política Nacional de Proteção dos Direitos da Pessoa com Transtorno do Espectro Autista dos Estados, do Distrito Federal e dos Municípios, mediante requerimento, acompanhado de relatório médico, com indicação do código da Classificação Estatística Internacional de Doenças e Problemas Relacionados à Saúde (CID), e deverá conter, no mínimo, as seguintes informações..." (BRASIL, 2020). 


\section{Danos causados ao aluno com espectro autista pela exclusão e o isolamento}

Do ponto de vista da educação inclusiva, o campo da educação especial requer a interseção entre saúde e educação. Portanto, o público-alvo pode ser identificado nas paredes da escola através do relatório médico emitido pelo psiquiatra ou neurologista, e o relatório identifica o aluno pela deficiência ou patologia descoberta. Somente de acordo com este documento é possível desenvolver um Plano de Desenvolvimento Individual (PDI) para adaptar o currículo da escola às necessidades dos alunos (PIMENTA PR, 2019).

A família é o primeiro ambiente social da criança e o principal ambiente para seus cuidados, tem o potencial de atender às suas necessidades, a fim de apoiar e promover seu potencial de desenvolvimento. Nessa perspectiva, o surgimento de doenças crônicas e seu manejo nas interações familiares é um desafio que pode determinar o enfraquecimento dos vínculos familiares e de sua estrutura. É na família que a inteiração social se dá pela primeira vez, e para a criança com autismo, a forma de inserção na sociedade será iniciada. A necessidade de tratamentos e acompanhamentos profissionais são sempre apresentadas, entretanto não se faz em todos os casos por inúmeros motivos, um deles e mais cruel é o preconceito e o desprezo social (MAPELLI LD, et al., 2018).

Embora o comportamento de crianças com espectro autista seja difícil de regular a interação e a comunicação social, e possa ter pouco interesse em estabelecer relacionamentos com diferentes níveis de dificuldade na reciprocidade social e emocional, concorda-se com a importância da interação social para as crianças. O conceito de desenvolvimento humano e bidirecionalidade é caracterizado pela ênfase na reciprocidade e na adaptação mútua entre parceiros, levando em consideração suas respectivas características. Da perspectiva da interação social linguística, foi exposta a importância do ambiente interpessoal para a aquisição de habilidades de comunicação, enfatizando o apoio dos adultos por eles serem sensíveis às necessidades de diálogo da criança, para que assim possam contribuir com a adaptação e contribuição à capacidade, isto é, os adultos ajustando seu comportamento comunicativo para obter a resposta das crianças (LEMOS ELMD, et al., 2014).

Para qualquer aluno que possua diferenças, a sala de aula pode se tornar um verdadeiro problema. Isso se dá pelas recentes implementações de políticas e adaptações às suas necessidades. Assim como o aluno cadeirante tem limitações e não pode chegar a todos os locais do ambiente escolar, o aluno com espectro autista também possui limitações e precisa contar com a sensibilidade do docente e dos outros alunos. Algumas diferenças entre pessoas com autismo fazem com que algumas não possam frequentar locais com muito barulho, ou que necessitem de mais tempo para desvendar situações de pouca complexidade para aqueles que não possuem o espectro. Estar em pleno contato com as necessidades desses alunos e programar um plano de aula acessível aos mesmos, é uma política essencial para evitar a exclusão e o isolamento (MARTELETO MRF, et al., 2011).

As formas de tratamento também colaboram para que o aluno com espectro autista se sinta ou não incluído nos ambientes. Não se trata de insensibilidade, mas uma questão abordada por estudos que apontam o tratamento de diferenças de atos e não incapacidade da pessoa. Os transtornos, por vezes, ao conhecimento popular, são tratados como loucura e pode levar ao afastamento das pessoas. Há que se programar formas de instruir a sociedade quanto as diferenças de surtos psicóticos das necessidades especiais do autista, para que dessa forma, além de não existir um tratamento diferenciado assemelhado ao tratamento dado a pessoas portadoras de outras doenças, possa fomentar a aproximação social e evidenciar que a pessoa com espectro autista tem dificuldades diferentes das dificuldades de quem não porta esse transtorno, e não possuem total incapacidade compreensiva (TONELLI H, 2011).

De todos os tratamentos diferenciados existentes, os danos estão sempre relacionados a dificuldades de adaptação, o que por vez dificulta no tratamento do aluno autista. Os tratamentos diferenciados, a ausência de comunicação adequada e a adaptabilidade dessas pessoas aos núcleos frequentados, provoca sofrimento e dor, já que é reconhecido do ser humano a necessidade de ser sociável. A inclusão, objeto do presente estudo, por muitas vezes não evidencia a mensagem que vem trazer e as pautas necessárias para a sua promoção. A ideia estará sempre atrelada a reduzir o sofrimento do excluído através do acolhimento correto e das abordagens pautadas no humanismo (PIMENTA PR, 2019). 


\section{CONSIDERAÇÕES FINAIS}

Arremata-se, portanto, que a saída para a inclusão requer preparo, políticas públicas incisivas e adaptações ambientais para o recebimento desses alunos. O professor que ainda não está preparado para tal demanda, deve ser preparado de maneira incisiva e própria, a fim de facilitar o contato do aluno com espectro autista com os outros alunos e todo o ambiente escolar. As formas de abordagem que são agressivas e inapropriadas sob a ótica inclusiva, estarão completamente fadadas a mudanças a partir do momento em que as políticas educacionais forem inteiramente adaptadas ao objeto de estudo desta revisão.

\section{REFERÊNCIAS}

1. ADURENS FDL, VIEIRA CM. Concepção de professores sobre a inclusão do aluno com autismo: uma pesquisa bibliográfica. Cadernos de Pós-Graduação em Distúrbios do Desenvolvimento, 2018; 18(2): 94-124.

2. ARAUJO JAMR, et al. Breves considerações sobre a atenção à pessoa com transtorno do espectro autista na rede pública de saúde. Revista Psicologia e Saúde, 2019; 11(1): 89-98.

3. BARBERINI KY. A escolarização do autista no ensino regular e as práticas pedagógicas. Cadernos de Pós-Graduação em Distúrbios do Desenvolvimento, 2016; 16(1): 46-55.

4. BENINI W, CASTANHA AP. A inclusão do aluno com transtorno do espectro autista na escola comum: desafios e possibilidades. Os desafios da escola pública paranaense na perspectiva do professor PDE, 2016; 1(1): 1-20.

5. BRASIL. 2019. In: AGÊNCIA Senado: Lei Romeo Mion cria carteira para pessoas com transtorno do espectro autista. Brasília: Senado Notícias. Disponível em: https:/www12.senado.leg.br/noticias/materias/2020/01/09/lei-romeo-mioncria-carteira-para-pessoas-com-transtorno-do-espectro-autista. Acesso em: 11 de jul. 2020.

6. BRASIL. 2020. In: LEI oㅜ 13.977, de 8 de janeiro de 2020: Altera a Lei oㅜ 12.764, de 27 de dezembro de 2012 (Lei Berenice Piana), e a Lei no 9.265, de 12 de fevereiro de 1996, para instituir a Carteira de Identificação da Pessoa com Transtorno do Espectro Autista (Ciptea), e dá outras providências. Brasília: Presidência da República. Disponível em: http://www.planalto.gov.br/ccivil_03/_ato2019-2022/2020/lei/L13977.htm. Acesso em: 12 de jul. 2020.

7. CABRAL CS, MARIN AH. Inclusão escolar de crianças com transtorno do espectro autista: uma revisão sistemática da literatura. Educação em Revista, 2017; 33(3): 1-18.

8. CAMARGO SPH, BOSA CA. Competência social, inclusão escolar e autismo: revisão crítica da literatura. Psicologia \& Sociedade, 2009; 21(1): 65-74.

9. FINK IC. Autismo e educação: possibilidades e estratégias de inclusão. Monografia (Trabalho de Conclusão de Curso do Curso de Pedagogia). Universidade do Vale do Taquari, Lajeado, 2018; 43 p.

10. GONÇALVES LP, et al. Contribuições da psicologia para inclusão escolar de crianças com transtorno do espectro autista no Município de Assis. Encontro de Ensino, Pesquisa e Extensão, 2014; 11(esp.): 1189-1197.

11. LEMOS ELMD. Inclusão de crianças autistas: um estudo sobre concepções e interações no contexto escolar. Dissertação (Mestrado em Psicologia Social). Universidade Federal da Paraíba, João Pessoa, $2012 ; 192$ p.

12. LEMOS ELMD, et al. Inclusão de crianças autistas: um estudo sobre interações sociais no contexto escolar. Revista Brasileira de Educação Especial, 2014; 20(1): 117-130.

13. MAIA FA, et al. Transtorno do espectro do autismo e idade dos genitores: estudo de caso-controle no Brasil. Cad. Saúde Pública, 2018; 34(8): 1-14.

14. MAPELLI LD, et al. Criança com transtorno do espectro autista: cuidado na perspectiva familiar. Escola Anna Nery, 2018; 22(4): 1-14.

15. MARTELETO MRF, et al. Problemas de Comportamento em Crianças com Transtorno Autista. Psicologia: Teoria e Pesquisa, 2011; 27(1): 5-12.

16. MARTINS ADF, MONTEIRO MIB. Alunos autistas: análise das possibilidades de interação social no contexto pedagógico. Psicologia Escolar e Educacional, 2017; 21(2): 215-224.

17. MAZZOTTA MJS, D'ANTINO MEF. Inclusão Social de Pessoas com Deficiências e Necessidades Especiais: cultura, educação e lazer. Saúde Soc., 2011; 20(2): 377-389.

18. NUNES DRP, SCHMIDT C. Educação especial e autismo: das práticas baseadas em evidências à escola. Cadernos de Pesquisa, 2019; 49(173): 84-103.

19. OLIVEIRA BDC, et al. Políticas para o autismo no Brasil: entre a atenção psicossocial e a reabilitação. Physis Revista de Saúde Coletiva, 2017; 27(3): 707-726.

20. PIMENTA PR. Clínica e Escolarização dos Alunos com Transtorno do Espectro Autista (TEA). Educação \& Realidade, 2019; 44(1): 1-15.

21. SILVA A, MULICK JA. Diagnosticando o transtorno autista: aspectos fundamentais e considerações práticas. Psicologia: Ciência e Profissão, 2009; 29(1): 116-131.

22. TONELLI H. Autismo, teoria da mente e o papel da cegueira mental na compreensão de transtornos psiquiátricos. Psicologia: Reflexão e Crítica, 2011; 24(1): 126-134.

23. WUO AS. Educação de pessoas com transtorno do espectro do autismo: estado do conhecimento em teses e dissertações nas regiões Sul e Sudeste do Brasil (2008-2016). Saúde Soc., 2019; 28(3): 210-223. 